\title{
Influence of chemical and thermal treatment on the purity of silica extracted from rice husk
}

\author{
Bahaa F. Shihab and Wesam A. A. Twej \\ Department of Physics, College of Science, University of Baghdad, Baghdad, Iraq \\ E-mail: bahaa_200011@yahoo.com
}

\begin{abstract}
In this work, chemical and thermal treatment were used to enhance silica extract on the purity of rice husk and to reduce the impurities associated with the extraction of silica. The thermal degradation of rice husk was studied. The characteristics and thermal degradation behavior of rice husk which investigated using thermogravimetric analyzer (TGA). Hydrochloric acid was used to soak the rice husk and the study of leaching influence is followed by XRF tests for samples before and after the combustion process. Acid treatment and combustion method seem to have a clear effect on silica purity. The pyrolysis processes were carried out at Laboratory temperature up to $650{ }^{\circ} \mathrm{C}$ in the presence of nitrogen gas flowing at $150 \mathrm{ml} / \mathrm{min}$. The effect of high combustion levels on the structure was also investigated through XRD testing.
\end{abstract}

Key words

Rice husk, silica, treatment.

Article info.

Received: Aug. 2018

Accepted: Sep. 2018

Published: Dec. 2018

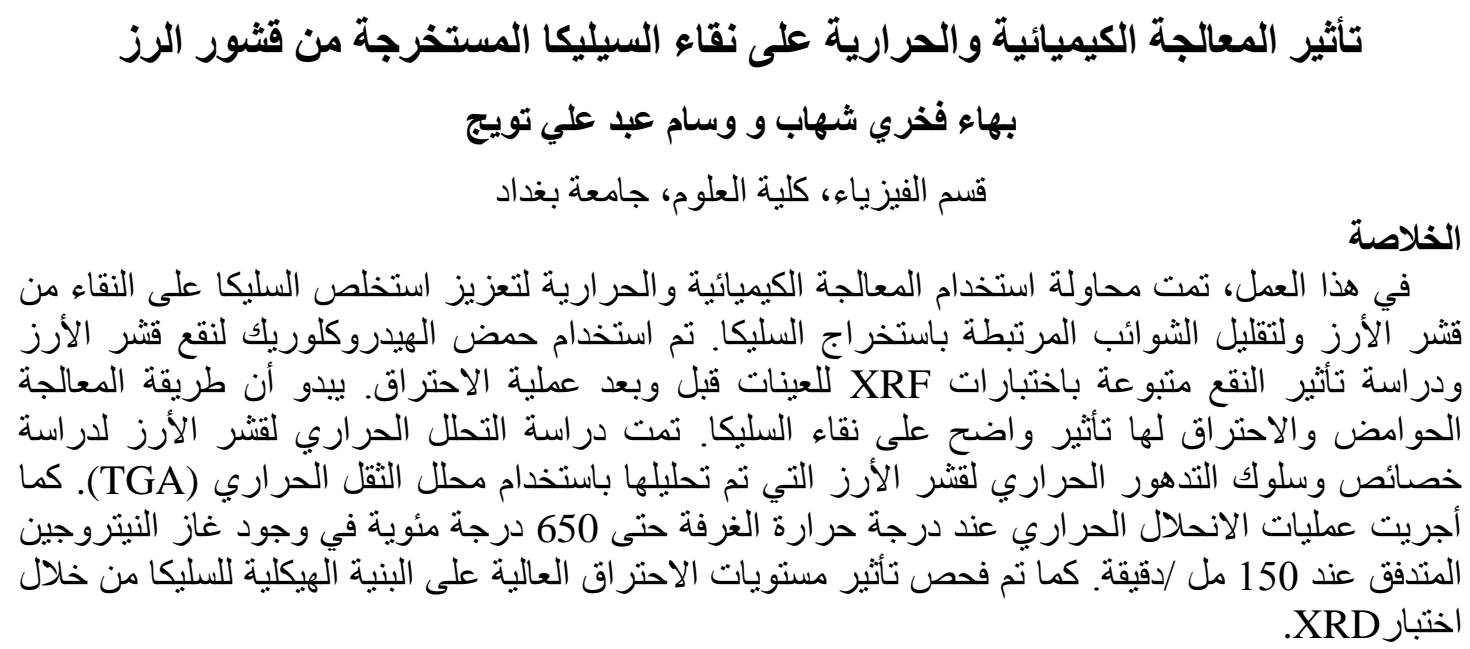

\section{Introduction}

Rice Husk (RH) are agricultural waste resulting from the milling of the crop of rice. It is a residue produced in significant quantity on a global basis. They are used as a fuel in some regions, in other countries they are treated as waste, they are usually disposed of by burning in the field, which results in damage to the either and the environment [1, 2]. It was found that RH contains good amounts of amorphous porous silica, containing about 15-20\% silica [3-5]. High levels of silica content have encouraged many researchers to research how amorphous silica is extracted with high purity [5].

Usually there is a lot of oxides with silica, such as $\mathrm{K}_{2} \mathrm{O}, \mathrm{CaO}, \mathrm{MgO}, \mathrm{MnO}$, $\mathrm{Al}_{2} \mathrm{O}_{3}, \mathrm{P}_{2} \mathrm{O}_{5}$, in different proportions. Which are considered undesirable [6, 
7]. The percentage of $\mathrm{K}_{2} \mathrm{O}$ is a high impurity, which is the main reason that ash is gray and not white, it is known that white ash is preferred because it contains a small percentage of carbon [8]. The effect of $\mathrm{K}_{2} \mathrm{O}$ ratios can be minimized by acid and thermal treatment.

Silica can be extracted from rice straw by burning RH using a furnace with control in time and combustion temperature, thereby turning into rice husk ash (RHA) containing 90-98\% amorphous silica [2]. Silica can be extracted from RHA since it is soluble under alkaline condition and which can be converted to sodium silicate (water glass) by the reaction of ash with sodium hydroxide according to the, as mentioned by A. Venkateswara Rao et al. [9].

\section{Methods}

\section{Raw materials}

RH was obtained from a local rice milling company in Najaf farms in Iraq. Hydrochloric acid (35\%, Merck, India). All chemicals were of Analytical Reagent (AR) grade and used directly without purification. Finally, distilled water supplied from our lab.

\section{Procedure}

\subsection{Rice husk ash preparation}

The RH was sieved using a $300 \mu \mathrm{m}$ sieve for removal the remains of small rice and to eliminate clay particles, then was washed thoroughly; firstly, with water and secondly with distilled water to remove any dust or adhering impurities

And were completely soaked in $\mathrm{HCl}$ solution at the concentration of $(1 \mathrm{M})$ for a period of one day. And then were rewashed, at least three times with distilled water for removing any residual hydrochloric acid. This process was gauged by reaching acidfree state, i.e. a neutral $\mathrm{pH}$. The purpose of the previous process was to remove the small quantities of minerals prior to silica extraction from RHA.

Drying the wet washed $\mathrm{RH}$ at $120{ }^{\circ} \mathrm{C}$ for several hours on a large baking dish, the moisture was almost being removed. It is recommended that the door of the used muffle furnace should be slightly opened in order to allow the water vapor to exit, as well as, the drying process should be carried out with stirring occasionally.

Picking out $200 \mathrm{~g}$ of milled $\mathrm{RH}$ and divided into two parts, each part $100 \mathrm{~g}$ were placed into medium-size porcelain crucibles. These crucibles were then placed inside the muffle furnace. The first part was burned by the muffle furnace directly to a temperature of $650{ }^{\circ} \mathrm{C}$, sample a. The second part was burned by the muffle furnace directly to a temperature of $300^{\circ} \mathrm{C}$ and kept at this temperature for $30 \mathrm{~min}$, and then the temperature was raised gradually from $300{ }^{\circ} \mathrm{C}$ to $500{ }^{\circ} \mathrm{C}$, at a rate of $50^{\circ} \mathrm{C}$ per 15 minutes, and kept it at this temperature until the smoke out stopped. The temperature raising continued at the same previous rate to $650^{\circ} \mathrm{C}$ Sample b. The two samples were annealed at $650{ }^{\circ} \mathrm{C}$ for 5h. Fig. 1 illustrate a schematic diagram for the adopted furnace.

The RHA samples then came out from the furnace, after cooling to room temperature inside the furnace. Finally, the obtained ash powders were weighed and saved in a suitable container for further investigations. 


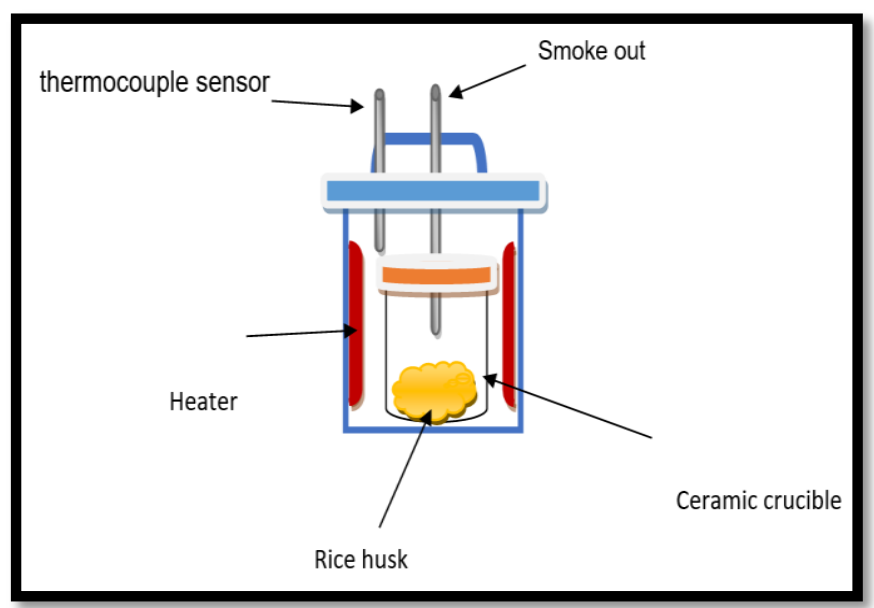

Fig .1: Furnace used to control the combustion process.

The RHA samples were then soaked in a hydrochloric acid $\mathrm{HCl}$ $(0.5 \mathrm{~N})$ for a one day, with stirring occasionally, to remove some of the remaining oxides, in order to get high purity silicate, sample (a to b) and (c to d) as shown in Fig. 2.
Additional thermal treatment in this work was employed by increasing the burning temperature for a sample of $\mathrm{RH}$ to $1000{ }^{\circ} \mathrm{C}$, the effect of high heat treatment on the structural properties for RHA has been analyzed. Fig. 2 shows the photograph of the resulting RHA samples.

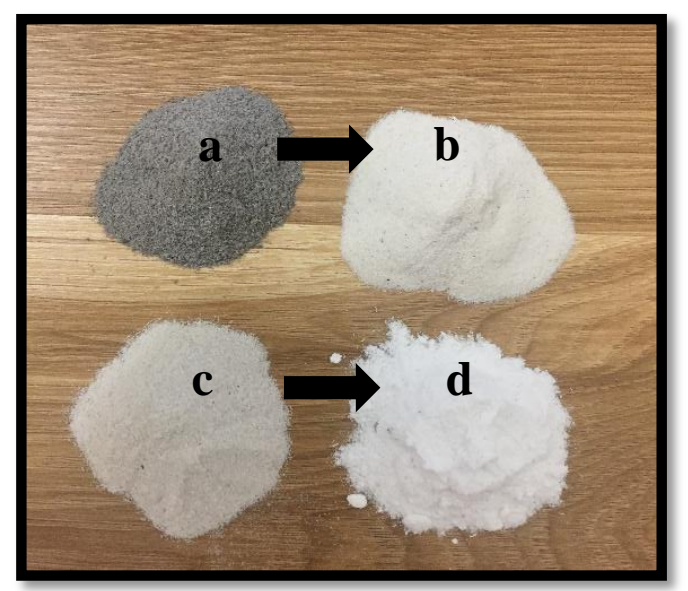

Fig. 2: Photograph of $a, b, c$, and d samples.

\section{Results and discussion}

Fig. 3 exhibits the TGA results of $\mathrm{RH}$ tested in an atmospheric environment. In the first phase, the moisture was removed from $\mathrm{RH}$ and this is at $125^{\circ} \mathrm{C}$ as indicated by $\sim 5 \%$ from the mass loss at this temperature. The second phase was representing the thermal decomposition, which started at $256{ }^{\circ} \mathrm{C}$ and ended at $375^{\circ} \mathrm{C}$ with the mass loss from $9 \%$ to $\sim 50 \%$. Thereafter, the third phase was finished at $440{ }^{\circ} \mathrm{C}$ with $\sim 54 \%$ mass loss, this phase may represent to the decomposition of relatively long chain carbonaceous material. In the fourth phase, it was finished at $480{ }^{\circ} \mathrm{C}$ with $\sim 61 \%$ mass loss. This corresponded to the totally converting of the carbons solid contain to gaseous carbon oxides. In 
the region from $480{ }^{\circ} \mathrm{C}$ to $600{ }^{\circ} \mathrm{C}$, it is usually referred to as a negative area, because no significant reduction in mass is observed which ingreement with [10]. In the final stage, mass loss was not interesting until $650^{\circ} \mathrm{C}$, and did not record any decline in the mass after this stage
[11]. It is important to mention here is our observations of the behavior of thermal decomposition during TGA results, the temperature for thermal treatment of acid-leached $\mathrm{RH}$ was chosen to be $650{ }^{\circ} \mathrm{C}$ to convert RH into white RHA.

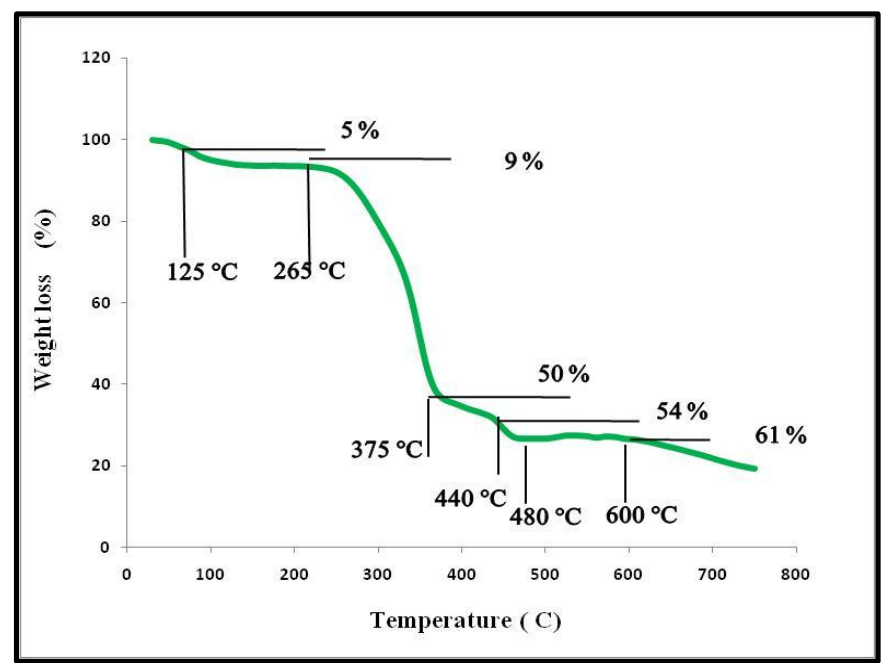

Fig. 3: Thermogravimetry (TGA) curves of $\mathrm{RH}$ in the nitrogen atmosphere.

Table 1 shows the percentage of $\mathrm{RH}$ components before and after chemical treatment by hydrochloric acid, examined by XRF. Where the results showed high-efficiency acid treatment in the removal of potash oxide $\mathrm{K}_{2} \mathrm{O}$, where the removal of up to $99 \%$ of the potassium concentration which could not remove by washing with water, because it does not dissolve easily in water.

It is worth noting that the high percentage of potassium oxide is the cause of the gray color of the ash, Gray indicates high ratios of carbon or the impurity ratio is high. This due to the strong interaction between potassium and silica which causes a form of potassium poly-silicate $\left(\mathrm{K}_{2} \mathrm{SiO}_{3}\right)$ on the surface of the $\mathrm{RH}$ from the first hour of combustion. It prevents carbon contact with the air so carbon does not volatilize even when combustion hours are increased [12, 13].
Table 1: XRF compositional analysis of RH.

\begin{tabular}{|c|c|c|}
\hline Materials & $\begin{array}{c}\text { washed by } \\
\mathrm{H}_{2} \mathrm{O}\end{array}$ & $\begin{array}{c}\text { washed by } \\
\mathrm{HCl} \text { as well }\end{array}$ \\
\hline $\mathrm{SiO}_{2}$ & $22.73 \%$ & $24.12 \%$ \\
\hline $\mathrm{KO}_{2}$ & $0.742 \%$ & $0.0066 \%$ \\
\hline Metal oxides & $1.878 \%$ & $1.4833 \%$ \\
\hline $\begin{array}{c}\text { Organic } \\
\text { component }\end{array}$ & $74.65 \%$ & $74.3901 \%$ \\
\hline
\end{tabular}

Table 2 shows the effect of combustion method and chemical treatment on the production of white ash from $\mathrm{RH}$ with high purity of silica.

As noted from the sample (a), when the $\mathrm{RH}$ is treated with $\mathrm{HCl}$, and the heat treatment at high temperature $650{ }^{\circ} \mathrm{C}$, the impurity ratio is high. This was due to the emergence of polysilicate $\mathrm{K}_{2} \mathrm{SiO}_{3}$ on the surface of the RH, sample (b) the acid treatment of sample (a) was carried out, and a decrease in impurities was observed with an increase in silica purity. 
Table 2: XRF compositional analysis of RHA samples.

\begin{tabular}{|c|c|c|c|c|}
\hline Contain & a & b & c & d \\
\hline $\mathrm{SiO}_{2}$ & $91.12 \%$ & $95.79 \%$ & $98.02 \%$ & $98.8 \%$ \\
\hline $\mathrm{MgO}$ & $0.354 \%$ & $0.25 \%$ & $0.002 \%$ & --- \\
\hline $\mathrm{P}_{2} \mathrm{O}_{5}$ & $1.15 \%$ & $1.033 \%$ & $0.78 \%$ & $0.67 \%$ \\
\hline $\mathrm{K}_{2} \mathrm{O}$ & $3.19 \%$ & $0.67 \%$ & $0.055 \%$ & $0.0013 \%$ \\
\hline $\mathrm{CaO}$ & $2.12 \%$ & $1.35 \%$ & $0.512 \%$ & $0.15 \%$ \\
\hline $\mathrm{Fe}_{2} \mathrm{O}_{3}$ & $0.772 \%$ & $0.4 \%$ & $0.233 \%$ & $0.16 \%$ \\
\hline Others & $1.294 \%$ & $0.507 \%$ & $0.398 \%$ & $0.2187 \%$ \\
\hline
\end{tabular}

At sample (c), the RH was slowly heated from $300{ }^{\circ} \mathrm{C}$ up to $650{ }^{\circ} \mathrm{C}$, during slow-heating, carbon oxidation in the $\mathrm{RH}$ was already taking place in the temperature band of $150-350^{\circ} \mathrm{C}$ before the dissociation of potassium oxide at $347^{\circ} \mathrm{C}$. Resulting in significant removal of impurities, led to producing white RHA, however, some black particles still exist. The result at the sample (d) appeared, that combined of acid treatment by $\mathrm{HCl}(0.5 \mathrm{M})$ for $\mathrm{RH}$ before and after the combustion process.

To obtain high-purity silica, the RHA that utilized followed sample (c) recipe should be soaked in $\mathrm{HCl}(0.5 \mathrm{M})$ to remove more impurities. The purity of RHA was reached about $99 \%$ by the final procedure (sample d).
The X-Ray Diffraction (XRD) of the RHA obtained from combustion of $\mathrm{RH}$ at $650^{\circ} \mathrm{C}$ sample(d), is shown in Fig. (4a). No specific peaks corresponding to the Bragg $2 \theta$ angles was observed. A broad hump was observed spanning the $2 \theta$ angle range of $18-30^{\circ}$ which is distinguished from the amorphous structure of silica. The lack of sharp peaks in this spectrum can confirm that acid treatment of $\mathrm{RH}$ did not affect the silica structure.

As the annealing temperature rises to $1000{ }^{\circ} \mathrm{C}$, sharp peaks were raised, besides the amorphous peaks, this indicates that some crystallites have been formed at $1000{ }^{\circ} \mathrm{C}$ in the $\mathrm{RH}$ combustion, as shown in Fig.(4b). This is consistent with conclusions of James and Rao [14]. 


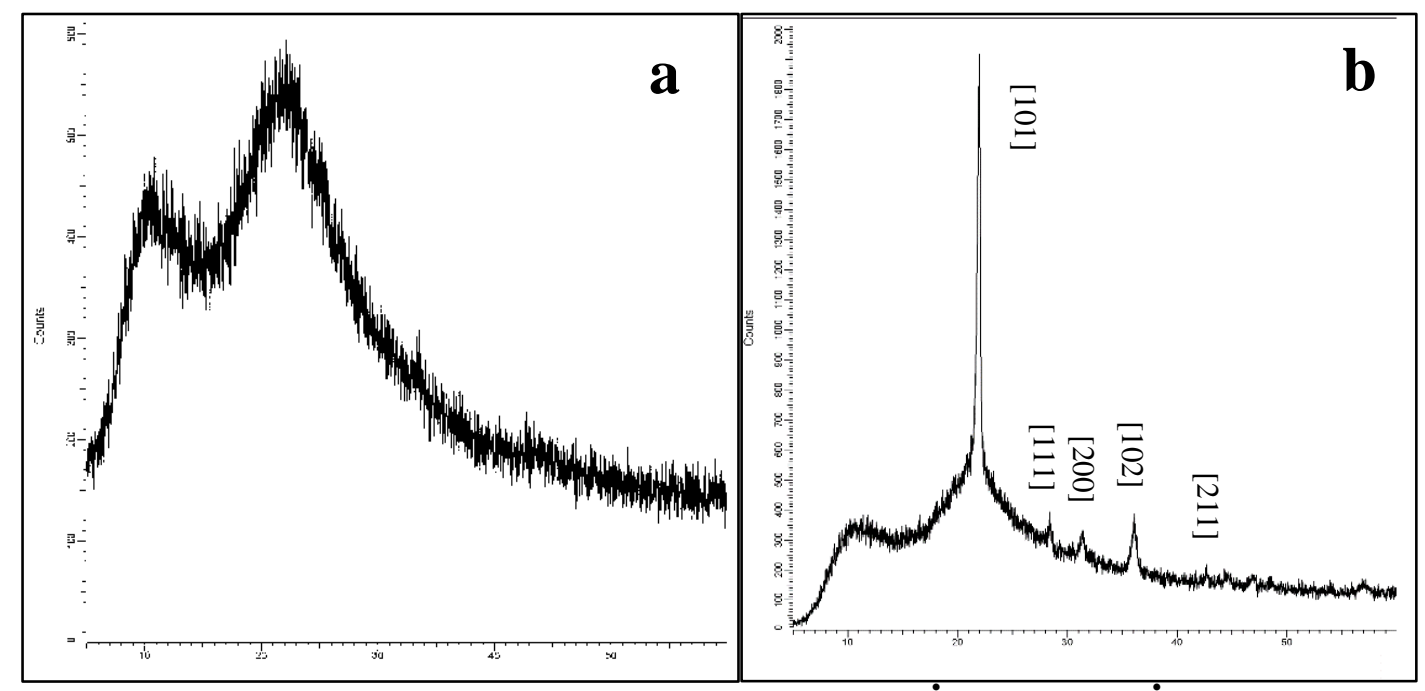

Fig. 4: XRD of RHA annealed (a) at $650^{\circ} \mathrm{C}$ (b) at $1000^{\circ} \mathrm{C}$.

Table 3 shows the RHA components annealed at of $1000{ }^{\circ} \mathrm{C}$ by XRF, it is clear that there is a significant reduction in the oxides percentage, it can interpret the result of reaching the degree of volatilization of some oxides.

Table 3: Components of RHA heat treated at a temperature of $1000^{\circ} \mathrm{C}$.

\begin{tabular}{|c|c|}
\hline Materials & Weight percentage \\
\hline $\mathrm{SiO}_{2}$ & $99.02 \%$ \\
\hline $\mathrm{MgO}$ & $0 \%$ \\
\hline $\mathrm{P}_{2} \mathrm{O}_{5}$ & $0.52 \%$ \\
\hline $\mathrm{K}_{2} \mathrm{O}$ & $0 \%$ \\
\hline $\mathrm{CaO}$ & $0.311 \%$ \\
\hline $\mathrm{Fe}_{2} \mathrm{O}_{3}$ & $0.067 \%$ \\
\hline Others & $0.082 \%$ \\
\hline
\end{tabular}

\section{Conclusions}

Successfully converting of $\mathrm{RH}$ to RHA via acidic leaching followed by combustion drying was done in this work. The findings from this research have shown the various colors and color blends of RHA. The acid concentration should be not less than $1 \mathrm{M}$, and the leaching period should be not less than two days, in order to obtain high purity silicate in the extraction of silica from RHA. It exhibits a potentially valuable, cheap alternative to the more expensive natural and synthetic silica for numerous industrial applications. This quest has stimulated a new-found interest in stuff from agro-waste materials having potential 'recyclability'. Their abundant availability, low-cost and recyclability has become a most important powerful factor in their utilization as industrial raw -materials.

\section{References}

[1] R. Patil, R. Dongre, J. Meshram, IOSR J. Appl. Chem, 2278, 5736 (2014) 26-29.

[2] M. Rosario, C. A. Nogueira, F. Margarido, 4th International Conference on Engineering for Waste and Biomass Valorisation, September, 5, 7 (2012) 10-13.

[3] Rohani Abu Bakarb, Rosiyah Yahya, Seng Neon Gana, Procedia Chemistry, 19 (2016) 189-195.

[4] R. S. Kumar, M. Vinjamur, M. Mukhopadhyay, International Journal of Chemical Engineering and Applications, 4, 5 (2013) 321-325.

[5] Wee-Keat Cheah, Chee-HeongOoi, Fei-Yee Yeoh, Mesoporous Biomater, 3 (2016) 27-38. 
[6] K. Kaviyarasu, E. Manikandan, J. Kennedy, M. Jayachandran, M. Maaza, Adv. Mater. Lett., 7, 9 (2016) 684-696. [7] Qi Tang, Tao Wang, J. of Supercritical Fluids, 35 (2005) 91-94.

[8] C. D. I. Ossi, Int. J. Appl. Chem., 12, 3 (2016) 281-291.

[9] A. Venkateswara Rao, A. Parvathy Rao, M. M. Kulkarni, J. Non. Cryst., Solids, 350 (2004) 224-229.

[10] M. V. Ramiah, J. Appl. Polym. Sci, 14, 5 (1970) 1323-1337.
[11] D. Angelova, I. Uzunov, S. Uzunova, A. Gigova, L. Minchev, Chem. Eng. J., 172, 1 (2011) 306-311. [12] R. V Krishnarao, J. Subrahmanyam, T. J. Kumar, J. Eur. Ceram. Soc., 21 (2001) 99-104. [13] C. D. I. Ossi, Int. J. Appl. Chem., 12, 3 (2016) 281-291.

[14] J. James and M. S. Rao, Thermochim. Acta, 97, 97 (1986) 329336. 